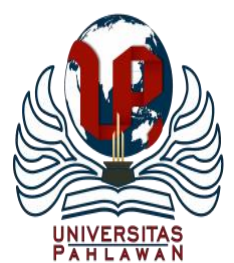

Jurnal Abdidas Volume 2 Nomor 1 Tahun 2021 Halaman 22-27

JURNAL ABDIDAS

http://abdidas.org/index.php/abdidas

\title{
Peningkatan Minat Baca Masyarakat Melalui Pengembangan Ruang Literasi dan Keperpustakaan di Dusun Coci, Kecamatan Pamboang, Kabupaten Majene
}

\author{
Andi Nur Fiqhi Utami ${ }^{1 \bowtie}$, Gia Ayu Fita ${ }^{2}$, Citra N. Fariaty ${ }^{3}$, Riady Ibnu Khaldun ${ }^{4}$ \\ Fakultas Ilmu Sosial dan Ilmu Politik, Universitas Sulawesi Barat, Majene, Indonesia ${ }^{1,2,3,4}$ \\ E-mail: anurfiqhiu@unsulbar.ac.id ${ }^{1}$, giaayufita@unsulbar.ac.id ${ }^{2}$, citranayy@gmail.com³ ${ }^{3}$, \\ riadyibnu@unsulbar.ac.id ${ }^{4}$
}

\begin{abstract}
Abstrak
Pada dasarnya literasi mempunyai arti berupa kemampuan dalam membaca dan menulis, sehingga sangat penting bagi seorang individu untuk memiliki tingkat literasi yang baik agar dapat mendukung tercapainya hidup yang lebih berkualitas dalam berkarya dan menggapai cita-cita. Demikian halnya, beberapa daerah di Indonesia masih menunjukkan tingkat aktivitas literasi yang rendah seperti di Provinsi Sulawesi Barat khususnya di Dusun Coci, Kecamatan Pamboang, Kabupaten Majene. Permasalahan tersebut satu di antaranya disebabkan oleh kurangnya ketersediaan akses literasi oleh masyarakat sekitar, maka untuk mendorong tingkat aktivitas literasi masyarakat dilakukan dengan upaya: 1) peningkatan kualitas taman baca mitra yaitu Taman Baca Coci melalui penambahan jumlah bahan bacaan yang disalurkan oleh para donatur melalui tim pengabdian masyarakat seperti buku bacaan anak, buku dengan tema politik, sosial, sejarah, maupun bukubuku lainnya yang bersifat umum; 2) peningkatan pengetahuan pengurus Lembaga Passikola Kapung tentang literasi dan keperpustakaan melalui pemberian materi yang disampaikan oleh anggota tim pengabdian masyarakat bertujuan untuk membangun kembali peranan penting lembaga mitra masyarakat dalam meningkatkan kesadaran masyarakat akan pentingnya literasi. Diharapkan dengan terlaksananya pengabdian masyarakat ini, akan memberikan dampak terhadap peningkatan aktivitas literasi masyarakat di Dusun Coci.
\end{abstract}

Kata kunci: literasi, keperpustakaan, kesadaran masyarakat

\begin{abstract}
Basically literacy means the ability to read and write, so it is very important for an individual to have a good level of literacy so that he can support the achievement of a higher quality life in work and reaching goals. Likewise, several regions in Indonesia still show a low level of literacy activity, such as in West Sulawesi Province, especially in Dusun Coci, Pamboang District, Majene Regency. One of these problems is due to the lack of availability of literacy access by the surrounding community, so to encourage the level of community literacy activities, efforts are made to: 1) improve the quality of Taman Baca Coci through increasing the number of reading materials distributed by donors through the community service team. society, such as children's books, books on political, social, historical themes, and other books of a general nature; 2) increasing the knowledge of Passikola Kapung Institute administrators about literacy and libraries through the provision of material delivered by members of the community service team aimed at rebuilding the important role of community partner institutions in increasing public awareness of the importance of literacy. It is hoped that the implementation of this community service will have an impact on increasing community literacy activities in Coci Village.
\end{abstract}

Keywords: literacy, library, citizen's awareness

Copyright (c) 2021 Andi Nur Fiqhi Utami, Gia Ayu Fita, Citra N. Fariaty, Riady Ibnu Khaldun $\triangle$ Corresponding author

Address : Universitas Sulawesi Barat

ISSN 2721- 9224 (Media Cetak)

Email : fiqhiandi@gmail.com

ISSN 2721- 9216 (Media Online)

DOI $\quad$ : https://doi.org/10.31004/abdidas.v2i1.194 


\section{PENDAHULUAN}

Kemajuan teknologi informasi yang terjadi saat ini menandakan adanya perkembangan fenomena informasi yang didukung dengan adanya perkembangan teknologi informasi (Sukrianto \& Oktarina, 2019). Adanya ledakan informasi ini menimbulkan melebarnya keterbatasan ruang, waktu, dan tempat dalam melakukan akses informasi, dikarenakan akses dapat dilakukan dimana saja dan kapan saja dengan memanfaatkan teknologi informasi. Dalam mengatasi ledakan informasi yang terjadi di masyarakat, maka perlu adanya pemahaman literasi informasi agar masyarakat dapat lebih bijaksana dalam menerima berbagai macam informasi (Nurwita et al., 2020). Kegiatan literasi selama ini identik dengan aktivitas membaca dan menulis, tetapi literasi juga mencakup bagaimana seseorang berkomunikasi dalam masyarakat (Budhianto, 2018). Seseorang yang terampil dalam literasi informasi mengenal waktu saat membutuhkan informasi serta memiliki kemampuan dalam melakukan penelusuran sampai dengan informasi yang ditemukan dan mampu melakukan evaluasi, serta mampu menggunakan informasi guna menentukan pengambilan keputusan yang tepat (Nugraha et al., 2019).

Individu yang memiliki informasi literasi akan menjadi pribadi yang memiliki rasa percaya diri, kemandirian, penuh inisiatif, dan memiliki motivasi tinggi dalam melakukan berbagai aktivitas. Selain itu, individu yang memiliki literasi informasi mengetahui cara belajar dan terus melakukan upaya untuk melakukan pembelajaran sepanjang masa (Winaryati, 2018). Ketika literasi informasi ini sudah dikuasai individu tersebut, maka akan lebih mudah dalam memanfaatkan informasi serta lebih mudah dalam menerapkan kreatifitas karena telah menguasai sumber-sumber informasi yang mendukung terciptanya kreatifitas dan juga dapat mendorong pencapaian kesuksesan akademik dari masyarakat akademik yakni berupa prestasi secara akademis maupun non akademis (Nofiana, 2017).

Dukungan perpustakaan dalam mendukung penciptaan lingkup akademik yang baik dan positif dapat dilakukan dengan membuat aktivitas literasi informasi untuk masyarakat akademik (Ridwan, 2019). Penguasaan literasi informasi ini sangat penting juga bagi masyarakat akademik karena diperlukan untuk mendukung pencapaian kesuksesan akademik maupun non akademik. Apabila masyarakat memiliki aktivitas literasi yang tinggi maka mereka dapat memanfaatkan keunggulan tersebut untuk berkreasi (Imran, 2010).

Hasil pengamatan oleh anggota tim pengabdian masyarakat menemukan bahwa tingkat aktivitas literasi yang rendah seperti di Provinsi Sulawesi Barat khususnya di Dusun Coci, satu di antaranya disebabkan oleh kurangnya ketersediaan akses literasi oleh masyarakat sekitar. Selain itu juga analisis situasi menemukan adanya permasalahan sebagai berikut, yaitu: 1) banyak sekali perpustakaan-perpustakaan di Indonesia yang telah berkembang dengan baik yang berstandar nasional yang menumbuhkan minat baca masyarakat. Berbeda sekali dengan taman baca mitra; 2) perbedaan kondisi taman bacaan 
masyarakat yang belum tertata dengan baik dibandingkan dengan perpustakaan yang terletak di perkotaan maupun perguruan tinggi; 3) bentuk pengelolaan taman baca terhadap sarana dan prasarananya yang belum lengkap dan memiliki standar koleksi perpustakaan, pelayanan atau manajemen, standar tenaga, standar penyelenggaraan, dan standar pengelolaan; 4) perbedaan kondisi sosial ekonomi dan politik masyarakat setempat di taman baca tidak didukung.

Dalam rangka untuk meningkatkan literasi masyarakat, maka anggota tim pengabdian mencari solusi yang dapat digunakan untuk memecahkan permasalahan seperti melakukan pengelolaan taman baca dengan baik dapat menghasilkan sumber daya yang terlibat dalam mendukung aktivitas pengelolaan taman baca tersebut, misalnya menggunakan sistem atau manajemen yang baik agar dapat digemari oleh generasi muda. Selanjutnya, mengadakan program pembinaan kemampuan membaca dan belajar masyarakat agar dapat mewujudkan masyarakat gemar membaca, mendukung pendidikan keaksaraan, dan berpikir kritis dan mendapatkan wawasan luas dalam kehidupan sehari-hari di masyarakat melalui lembaga mitra masyarakat yang ada di Dusun Coci, Kecamatan Pamboang, Kabupaten Majene.

\section{METODE}

Kegiatan pengabdian masyarakat ini khususnya pemberian materi dilaksanakan pada hari Minggu, tanggal 06 Desember 2020 bertempat di Dusun Coci, Desa Banua Adolang, Kecamatan
Pamboang, Kabupaten Majene, Sulawesi Barat. Selanjutnya, kegiatan penyaluran buku juga dilakukan di hari yang sama namun masih berlangsung hingga di bulan Januari 2021 dari anggota tim pengabdian lainnya.

Dalam kegiatan penyaluran literatur berupa buku yang berasal baik dari anggota tim pengabdian masyarakat maupun donatur di mana jenis buku yang disumbangkan berupa buku-buku bacaan anak serta buku lainnya seperti buku dengan tema politik, sosial, sejarah, biografi, dan lain-lainnya yang bersifat umum. Adapun pada pemberian materi yang dilakukan oleh dua anggota tim pengabdian kepada beberapa pengurus Lembaga Passikola Kapung dan Taman Baca Coci dengan muatan materi berupa Literasi Indonesia dan Keperpustakaan berisikan penjelasan tentang cara menyusun dan pengelolaan taman baca atau perpustakaan.

\section{HASIL DAN PEMBAHASAN}

Adapun jumlah peserta yang mengikuti kegiatan ini yakni 13 orang terdiri dari pemuda pemudi yang berasal dari Dusun Coci di mana sebagian peserta menunjukkan antusiasme yang tinggi dengan menceritakan berbagai macam pengalaman dari setiap peserta tentang perkembangan literatur dan perpustakaan di Indonesia. Selain itu juga berupa penyampaian beberapa informasi terkait dengan kendala serta tantangan dalam pengelolaan taman baca di desa khususnya di Dusun Coci. 


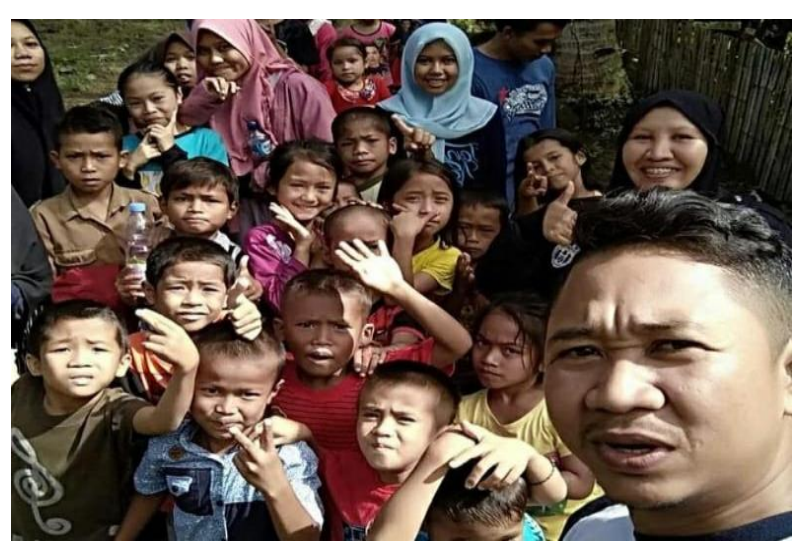

Gambar 1. Foto Bersama di Dusun Coci

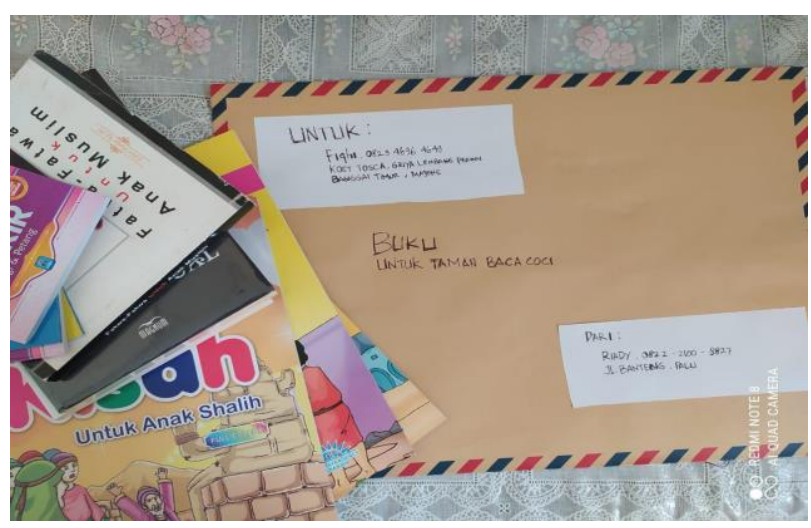

Gambar 2. Donasi Buku untuk Taman Baca Coci

Dalam pelaksanaan kegiatan pengabdian kepada masyarakat ini mendapatkan respon positif dari para peserta yang diharapkan dapat mendorong peningkatkan tingkat aktivitas literasi di Dusun Coci. Hal tersebut terwujud dari partisipasi para peserta baik segi jumlah maupun pemberian respon pada saat sesi tanya jawab berlangsung seperti halnya pertanyaan yang disampaikan oleh Ilham selaku pengurus Lembaga Passikola Kapung yang menanyakan terkait derngan apa saja yang diperlukan dalam memanajemen taman baca agar lebih menarik perhatian khususnya ke anak-anak yang sebetulnya menjadi fokus utama pembangunan Taman Baca Coci tersebut. Kemudian, Aswat yang juga pengurus Lembaga Passikola Kapung lainnya juga memberikan pertanyaan terkait dengan status buku yang telah terbit 5 tahun terakhir masih dianggap relevan dengan kehidupan sekarang. Selain itu, peserta lainnya yakni Arifin juga memberikan respon berupa permintaan kepada anggota tim pengabdian masyarakat yang menjadi pemateri untuk membantu menyampaikan suara kepada pemerintah daerah agar dapat memfasilitasi taman baca sehingga dapat berfungsi dengan baik serta tepat sasaran dalam rangka mendukung peningkatan aktivitas literasi masyarakat.

Berdasarkan informasi yang terhimpun menunjukkan bahwa masyarakat di Dusun Coci mayoritas memiliki tingkat pendidikan yang rendah seperti hanya sebatas lulusan Sekolah Menengah Pertama (SMP) dan tidak tertarik untuk melanjutkan pendidikannya. Sejatinya dengan mendorong tingkat aktivitas literasi masyarakat dapat mewujudkan tercapainya hidup yang lebih berkualitas dalam berkarya dan menggapai citacita karena literasi merupakan kemampuan setiap individu masyarakat dalam menulis maupun membaca. Dengan terciptanya minat baca yang tinggi oleh masyarakat Dusun Coci diharapkan dapat mewujudkan tujuan tersebut.

Selanjutnya, dalam kegiatan tersebut juga para peserta menyampaikan masukan berupa menginginkan anggota tim pengabdian untuk tidak hanya melakukan kegiatan ini hanya satu kali. Akan tetapi dapat melakukan kegiatan setiap 3 atau 6 bulan sekali dengan tujuan agar baik seluruh pengurus Taman Baca Coci, Lembaga Passikola Kapung, maupun masyarakat Dusun Coci dapat 
merasakan manfaat dari taman baca tersebut untuk mendorong peningkatan aktivitas literasi. Sehingga, dampak yang ditimbulkan dari kegiatan ini yaitu: 1) masyarakat Dusun Coci yang mengikuti kegiatan pembagian buku, mengetahui dan memahami bagaimana mereka akan meminjam buku dan buku apa yang akan mereka baca untuk menambah wawasan mereka; 2) pengurus lembaga Taman Baca Coci mendapatkan pencerahan mengenai cara mengelola taman baca; 3) mendapatkan bantuan penyaluran buku dari para donatur maupun anggota tim pengabdian masyarakat.

Adapun tindak lanjut dari kegiatan pengabdian kepada masyarakat ini adalah mengupayakan terjalinnya hubungan kerjasama Universitas Sulawesi Barat selaku institusi dengan Lembaga Taman Baca Coci selaku mitra. Ada pun aspek yang akan dievaluasi adalah kemampuan pengurus lembaga taman baca dalam mengaplikasikan pengetahuannya mengelola taman baca tersebut dari segi tata kelola manajemen, memantau buku-buku yang menjadi koleksi taman baca agar dapat menambah wawasan masyarakat di Dusun Coci. Diharapkan ke depannya juga akan terlaksana kegiatan serupa namun dengan topik yang berbeda untuk mendukung keberlanjutan dari beberapa kegiatan sebelumnya.

\section{SIMPULAN}

Berdasarkan analisis situasi dan hasil kegiatan yang telah dilakukan, maka dapat disimpulkan bahwa: 1) kegiatan ini memberikan banyak sekali pengetahuan dan inovasi baru bagi seluruh masyarakat sekolah dan umum di Dusun Coci mengenai buku-buku yang bermanfaat dan menunjang wawasan dan minat baca mereka; 2) kegiatan ini juga memberikan banyak keahlian dan ide-ide yang mencerahkan pengurus taman baca di Dusun Coci.

\section{UCAPAN TERIMA KASIH}

Segenap anggota tim pengabdian masyarakat ingin mengucapkan terima kasih kepada Dekan FISIP serta Ketua LPPM dan PM Universitas Sulawesi Barat. Selanjutnya, ucapan terima kasih diberikan kepada Kepala Dusun Coci, Taman Baca Coci, dan seluruh pengurus Lembaga Passikola Kapung atas kesediaannya untuk menerima tim pengabdian masyarakat melaksanakan seluruh proses kegiatan.

\section{DAFTAR PUSTAKA}

Budhianto, Y. (2018). Pembelajaran Bahasa Sebagai Upaya Meningkatkan Kemampuan Literasi Siswa. FON: Jurnal Pendidikan Bahasa Dan Sastra Indonesia. https://doi.org/10.25134/fjpbsi.v13i2.1550

Imran, H. A. (2010). Literasi Teknologi Informasi dan Komunikasi Masyarakat Pedesaan. Jurnal Studi Komunikasi Dan Media.

Nofiana, M. (2017). Profil Kemampuan Literasi Sains Siswa SMP di Kota Purwokerto Ditinjau dari Aspek Konten, Proses, dan Konteks Sains. JSSH (Jurnal Sains Sosial Dan Humaniora). https://doi.org/10.30595/jssh.v1i2.1682

Nugraha, J., MS, Z., \& Fuad, N. (2019). Peningkatan keterampilan menulis deskripsi melalui pendekatan saintifik dengan metode problem based learning di kelas iv sekolah dasar. Prosiding Seminar Nasional 

Nayasari Fahriaty, Riady Ibnu Khaldun

DOI : https://doi.org/10.31004/abdidas.v2i1.194

Pendidikan

KALUNI.

https://doi.org/10.30998/prokaluni.v2i0.37

Nurwita, N., Susanti, F., Permada, D. N. R., Oktrima, B., \& Irawati, L. (2020). Dampak Buruk Pemakaian Media Sosial Terhadap Semangat Dan Capaian Belajar Siswa Smp Arraisiyah Pamulang. Jurnal ABDIMAS Tri Dharma

Manajemen.

https://doi.org/10.32493/abmas.v1i1.p66-

76.y2019

Ridwan, M. M. (2019). Pengaruh Gaya Kepemimpinan Terhadap Motivasi Kerja Pustakawan Di Perpustakaan Universitas Muhammadiyah Yogyakarta: Studi Penerapan Gaya Kepemimpinan Path-Goal. Pustakaloka.

https://doi.org/10.21154/pustakaloka.v11i1.1 601

Sukrianto, D., \& Oktarina, D. (2019). Pemanfaatan Teknologi Barcode Pada Sistem Informasi Perpustakaan Di Smk Muhammadiyah 3 Pekanbaru. JOISIE (Journal Of Information Systems And Informatics Engineering). https://doi.org/10.35145/joisie.v1i2.216

Winaryati, E. (2018). Penilaian Kompetensi Siswa Abad 21. Prosiding Seminar Nasional \& Internasional. 